Article

\title{
Sustainable Development and Canada's Transitioning Energy Systems
}

\author{
Michael Benson ${ }^{1, *}$, Chad Boda ${ }^{2}$, Runa R. Das ${ }^{1}$, Leslie King ${ }^{3}$ and Chad Park ${ }^{4}$ \\ 1 College of Interdisciplinary Studies, Royal Roads University, Victoria, BC V9B 5Y2, Canada; \\ runa.das@royalroads.ca \\ 2 Lund University Centre for Sustainability Studies, P.O. Box 170, SE-222 70 Lund, Sweden; \\ chad.boda@lucsus.lu.se \\ 3 School of Environment and Sustainability, Royal Roads University, Victoria, BC V9B 5Y2, Canada; \\ leslie.king@royalroads.ca \\ 4 The Co-Operators Group Limited, Guelph, ON N1H 6P8, Canada; chadleepark@gmail.com \\ * Correspondence: michael.3benson@royalroads.ca
}

check for updates

Citation: Benson, M.; Boda, C.; Das, R.R.; King, L.; Park, C. Sustainable Development and Canada's Transitioning Energy

Systems. Sustainability 2022, 14, 2213. https://doi.org/10.3390/su14042213

Academic Editors: Harrie

Vredenburg and Connie Van der Byl

Received: 1 December 2021

Accepted: 11 February 2022

Published: 15 February 2022

Publisher's Note: MDPI stays neutral with regard to jurisdictional claims in published maps and institutional affiliations.

Copyright: (c) 2022 by the authors. Licensee MDPI, Basel, Switzerland. This article is an open access article distributed under the terms and conditions of the Creative Commons Attribution (CC BY) license (https:// creativecommons.org/licenses/by/ $4.0 /)$.

\begin{abstract}
An energy transition is unfolding in Canada and across the world. During this transition, countries are facing increasing demands for their energy systems to address economic, social, and environmental considerations, including providing affordable and reliable energy, reducing inequality, and producing fewer environmental impacts. First, we identify key themes from the academic literature related to energy transitions: the systems perspective; economic, social, and environmental considerations; collaboration and dialogue; and social innovation. Second, we focus on a case study of a critical actor in Canada's energy transition, the Energy Futures Lab (EFL), a social innovation lab that is actively working on the energy transition in Canada. We interviewed members of the EFL design team to investigate and deepen our understanding of the key themes identified in the academic literature. Third, we discuss how our research results relate to innovation and governance in the energy transition in Canada, and we offer an Integrated Model of Sustainable Development (SD) to help manage the common affairs of the energy transition. Fourth, we offer a theoretical contribution, arguing that both the ends and the means should be considered in an energy transition. It is important to keep in mind the overarching objective, or end, of the energy transition (e.g., alignment with the sustainability principles) to create the energy system that the future requires of us. Finally, we offer a practical contribution to show that SD can help inform a collaborative approach, that promotes innovation and increases knowledge, in an effort to address complex sustainability challenges.
\end{abstract}

Keywords: sustainable development; energy system; energy transitions; Canada

\section{Introduction}

A global energy transition is occurring, bringing with it both challenges and opportunities [1]. Canada, a country that is a significant global energy producer and has a high per capita energy consumption, is facing tremendous disruptions (e.g., fluctuating global energy prices, changing costs of energy production, increasing electrification, and rising demands for low-emissions energy) that are likely to continue for decades [2]. There is no "one size fits all" solution for successfully navigating this transition because context matters. That is, solutions will vary from country to country, and depend on factors such as available energy sources, geography, climate, environmental impacts, energy security, and politics. In Canada, the roadmap could possibly include increasing social innovation and new governance models. These factors also contribute to the inherent nature of energy systems as complex systems and, therefore, any solutions need to take into consideration existing collective knowledge about complex sustainability challenges [3,4].

Energy systems are expected to produce more affordable, reliable, and modern energy in order to reduce global inequality. For example, in 2017, 840 million people did not have 
access to electricity, almost 3 billion people relied on wood, coal, charcoal or animal waste for cooking and heating [5], 689 million people were living below the USD 1.90-a-day extreme poverty line, and 2 billion people were living below their countries' respective societal poverty line [6]. On the other hand, energy systems are also expected to contribute to fewer adverse environmental impacts (e.g., greenhouse gas emissions, local air and water quality, biodiversity, and biogeochemical cycles and flows). These different societal expectations for energy systems (i.e., reducing inequality and reducing environmental impacts) highlight the important role that energy systems have in creating a "safe and just space for humanity" [7] (p. 9).

Different societal expectations represent different priorities for energy transitions, creating tensions, trade-offs, and synergies. Normative considerations (e.g., distribution, justice and fairness) are a part of energy transitions [8]. For example, we can see normative considerations reflected in the speech from Barack Obama to the 26th UN Climate Change Conference of the Parties when he stated: "transitioning from dirty energy to clean energy does have a cost $(\ldots)$ we need to make sure the people most affected by the transition to clean energy aren't the ones bearing most of the costs". This is not unique to energy transitions, as similar challenges are faced in achieving sustainable development goals [9]. This article, using the example of Canada, investigates how societal expectations relate to the purpose, content, and strategy of energy transitions. We investigate these issues through the specific case of the Energy Futures Lab (EFL), which is actively working on the energy transition in Canada.

Drawing on the results of our case study, we discuss how sustainable development (SD) is one of the few concepts that embraces the wide range of considerations in an energy transition (e.g., social innovation; collaboration; systems perspective; social, environmental, and economic considerations; and multiple strategies), and provides a framework to help manage the tensions and trade-offs in an energy transition. SD is a dynamic process that meets the needs and prompts the capabilities of the current generation without compromising future generations [10-12]. As a result, SD is not only useful but necessary to navigate the complexities associated with Canada's energy transition.

This article aspires to make two contributions. From a theoretical perspective, both the ends and the means are important to consider in an energy transition. There are many important means to achieve the energy transition (e.g., reducing greenhouse gas emissions, reconciling with Indigenous peoples, protecting biodiversity, decreasing inequality, alleviating energy poverty, improving energy efficiency, removing anthropogenic nitrogen, and collaborating with citizens), and much more work needs to be conducted on these means. However, there needs to be equal consideration to the overarching objective, or end, of the energy transition (e.g., alignment with the sustainability principles) in order to create the energy system that the future requires of us. From a practical perspective, SD can inform a collaborative approach to addressing complex sustainability challenges that brings people together. The collaborative potential of SD exists because it is a sufficiently broad concept that enables people with different interests to find common ground. This collaborative approach stands in contrast to the polarizing approach of relying on SD to challenge the status quo, to point out deficiencies, and to highlight where we are falling short of achieving a perfectly sustainable society.

\section{Theoretical Framework: Four Key Themes Regarding Energy Transitions and Sustainable Development}

This initial section describes our theoretical framework; specifically, it outlines key themes expressed in the academic literature related to energy transitions. The literature related to energy transitions is broad; we aim here to provide the reader with a sense of how we are positioned in the literature and how we understand key concepts related to energy transitions. Key themes are based on concepts being highlighted across the academic literature. This theoretical framework informs our research and analysis of the energy transition that is happening in Canada. 
Transitions are fundamental shifts over the long term that include significant uncertainty [13]. It is possible to influence a transition using various types of steering and coordination, but no single actor has the ability to control the entire system. Within transition studies, there are several different frameworks, including transition management [14], technological innovation systems [15], the multi-level perspective on socio-technical transitions [16], just transitions [17], and sustainability transitions [18]. All of these frameworks provide valuable insights. For our purposes, the sustainability transition concept in particular provides a useful perspective, as it views energy transitions as fundamental shifts that promote more sustainable patterns of consumption and production [18], which are central concerns of energy transitions in general and in Canada in particular.

\subsection{Key Theme \#1: Energy Transitions Require a Systems Perspective}

Energy systems are understood here as "arrangements whereby humans use the Earth's resources to improve their chances of survival and to enhance their quality of life", and they are composed of the following elements: "energy sources, their conversions, and specific uses of energy flows" [19] (p. 1). A systems perspective allows us to better understand the interconnectedness of these elements, and identify potential challenges and opportunities to influence the energy transition [20]. A systems perspective ensures that we are not focused solely on one element of the system, such as the production of energy, in considering energy transitions. Table 1 illustrates the elements of energy systems.

Table 1. Matrix of Energy Conversions in an Energy System.

\begin{tabular}{|c|c|c|}
\hline Energy Sources & $\begin{array}{c}\text { Examples of Conversion } \\
\text { of Energy Sources }\end{array}$ & Uses of Energy Flows \\
\hline Electro-magnetic (light) & $\begin{array}{ll}\text { - } & \text { Photosynthesis } \\
\text { - } & \text { Solar photovoltaic cells } \\
\text { - } & \text { Solar absorption }\end{array}$ & $\begin{array}{ll}\text { - } & \text { To chemical energy } \\
\text { - } & \text { To electrical energy } \\
\text { - } & \text { To thermal energy }\end{array}$ \\
\hline $\begin{array}{l}\text { Chemical (from fuels and } \\
\text { foodstuffs) }\end{array}$ & $\begin{array}{ll}\text { - } & \text { Metabolism } \\
\text { - } & \text { Combustion } \\
\text { - } & \text { Fuel cells } \\
\text { - } & \text { Chemical processing }\end{array}$ & $\begin{array}{ll}\text { - } & \text { To kinetic energy } \\
\text { - } & \text { To thermal energy } \\
\text { - } & \text { To electrical energy } \\
\text { - } & \text { To chemical energy }\end{array}$ \\
\hline Nuclear & $\begin{array}{ll}\text { - } & \text { Fission/fusion } \\
\text { - Nuclear bombs }\end{array}$ & $\begin{array}{ll}\text { - } & \text { To thermal energy } \\
\text { - } & \text { To electro-magnetic } \\
\text { energy }\end{array}$ \\
\hline Kinetic (motion) & $\begin{array}{ll}\text { - } & \text { Friction } \\
\text { - } & \text { Gears } \\
\text { - } & \text { Electricity generation }\end{array}$ & $\begin{array}{ll}\text { - } & \text { To thermal energy } \\
\text { - } & \text { To kinetic energy } \\
\text { - } & \text { To electrical energy }\end{array}$ \\
\hline Thermal (heat) & $\begin{array}{ll}- & \text { Boiling } \\
\text { - } & \text { Thermal } \\
& \text { expansion/internal } \\
& \text { combustion }\end{array}$ & $\begin{array}{l}\text { - To chemical energy } \\
\text { - } \quad \text { To kinetic energy }\end{array}$ \\
\hline Electrical (converted energy) & $\begin{array}{ll}\text { - } & \text { Electrolysis } \\
\text { - } & \text { Resistance hearing } \\
\text { - } & \text { Electric motors }\end{array}$ & $\begin{array}{ll}\text { - } & \text { To chemical energy } \\
\text { - } & \text { To thermal energy } \\
\text { - } & \text { To kinetic energy }\end{array}$ \\
\hline
\end{tabular}

Source: adapted from [21].

Energy systems around the world are expected to produce and deliver not only affordable and reliable energy (which has long been the expectation), but also sustainable energy, such as low-emissions energy. The latter is a relatively more recent expectation, formed approximately when the first binding international climate treaty, the Kyoto Protocol, was adopted in 1997 [2]. This represents a major challenge for energy systems. For example, we can take a closer look at electricity generation, which is just one element in energy systems. From the economic perspective, the median levelized costs of generating electricity were 88 USD/MWh for coal, 71 USD/MWh for natural gas (CCGT), 69 USD/MWh for nuclear, 
50 USD/MWh for onshore wind, 88 USD/MWh for offshore wind, 56 USD/MWh for utility scale solar PV, 126 USD/MWh for residential solar PV, 72 USD/MWh for hydro, 99 USD/MWh for geothermal, and 118 USD/MWh for biomass [22]. From the environmental perspective, the median harmonized life cycle GHG emissions of electricity generation were approximately $975 \mathrm{~g} \mathrm{CO}_{2} \mathrm{eq} / \mathrm{kWh}$ for coal, $480 \mathrm{~g} \mathrm{CO}_{2} \mathrm{eq} / \mathrm{kWh}$ for natural gas, $10 \mathrm{~g}$ $\mathrm{CO}_{2} \mathrm{eq} / \mathrm{kWh}$ for nuclear, $12 \mathrm{~g} \mathrm{CO}_{2} \mathrm{eq} / \mathrm{kWh}$ for wind, $45 \mathrm{~g} \mathrm{CO}_{2} \mathrm{eq} / \mathrm{kWh}$ for solar photovoltaics, and $8 \mathrm{~g} \mathrm{CO}_{2} \mathrm{eq} / \mathrm{kWh}$ for hydropower [23]. From the societal perspective, there are varying levels of social acceptance for different generation technologies, and there are varying levels of availability for energy sources from region to region. As a result, every region has developed its own unique energy system, including, but not limited to, elements for electricity generation, based on many factors, including the trade-offs between short-term and long-term considerations, and between society, economy, and environment.

\subsection{Key Theme \#2: Energy Transitions Involve Social, Environmental, and Economic Considerations}

Energy systems (i.e., energy sources, their conversion, and specific uses) have positive and negative impacts on society that include social, environmental, and economic considerations. Energy transitions involve trade-offs among these impacts, which must be identified and assessed by governance models in order to promote more sustainable patterns of consumption and production. SD is one of the more mature and widely accepted concepts that embraces trade-offs and links together social, environmental, and economic considerations. SD was popularized in 1987 with the release of the United Nations report Our Common Future, where it was defined as "development that meets the needs of the present without compromising the ability of future generations to meet their own needs" [10] (p. 8).

Since the release of the Brundtland Report, there have been substantive deliberations aimed at interpreting and operationalizing the concept of SD. These deliberations have identified the essential components of SD to include intergenerational equity, as well as the relationship among environment, economy, and society. SD adopts an interdisciplinary and systems-based approach to understanding complex challenges and developing practical solutions. There is increasing acceptance that SD should be thought of as a dynamic process that moves us towards a better future, as opposed to specific goals that need to be achieved [12].

Following the publication of the Brundtland Report, Karl-Henrik Robèrt developed The Framework for Strategic Sustainable Development (FSSD), popularized as The Natural Step Framework [24], which established sustainability principles for sustainable human activities on Earth $[25,26]$. This openly published framework is based on systems thinking [27], and is meant to be used for planning in complex systems. Table 2 lists the four sustainability principles from the FSSD, which indicate that achieving a sustainable society requires a focus on systematic increases in a variety of areas.

Table 2. Sustainability Principles from the Natural Step Framework.

\begin{tabular}{|c|c|}
\hline \multicolumn{2}{|r|}{ In a Sustainable Society, Nature is Not Subject to Systematically Increasing } \\
\hline & concentrations of substances from the Earth's crust (such as fossil $\mathrm{CO}_{2}$ and heavy metals), \\
\hline & $\begin{array}{l}\text { concentrations of substances produced by society (such as antibiotics and } \\
\text { endocrine disruptors), }\end{array}$ \\
\hline 3. & degradation by physical means (such as deforestation and draining of groundwater tables), \\
\hline \multicolumn{2}{|c|}{... and in that society } \\
\hline & $\begin{array}{l}\text { there are no structural obstacles to people's health, influence, competence, impartiality, and } \\
\text { meaning making. }\end{array}$ \\
\hline
\end{tabular}


These sustainability principles can be used to evaluate whether we are promoting more sustainable patterns of consumption and production, and thus help link the concept of sustainability transition to the over-arching process of SD.

Within SD, there are different strategies and associated tools that could be applied to projects, policies, and initiatives to help decide among options and manage tradeoffs. The two main SD approaches are the Capital Theory Approach and the Human Development Approach, and within each approach, there are three main SD decisionmaking strategies: economic choice (e.g., relying on market mechanisms), political choice (e.g., relying on government intervention), and social choice (e.g., relying on the values of citizens) $[28,29]$. These SD strategies correspond to the SD approaches of weak sustainability, strong sustainability, and human development. Table 3 provides an overview of these SD approaches.

Table 3. Overview of Sustainable Development Approaches.

\begin{tabular}{|c|c|c|c|c|}
\hline \multicolumn{2}{|c|}{ SD Approach } & SD Strategy & SD Tools & Concepts \\
\hline \multirow{2}{*}{$\begin{array}{l}\text { Capital } \\
\text { Theory } \\
\text { Approach }\end{array}$} & Weak Sustainability & Economic Choice & Cost Benefit Analysis & $\begin{array}{l}\text { Productive Capacity } \\
\text { Total Capital Stock } \\
\text { Capital Substitution }\end{array}$ \\
\hline & Strong Sustainability & Political Choice & $\begin{array}{c}\text { Conservation, Steady } \\
\text { State Policies }\end{array}$ & $\begin{array}{c}\text { Productive Capacity } \\
\text { Natural Capital Stock } \\
\text { Capital } \\
\text { Complementarity }\end{array}$ \\
\hline $\begin{array}{l}\text { Human } \\
\text { Development } \\
\text { Approach }\end{array}$ & Capability Approach & Social Choice & $\begin{array}{l}\text { Public Participation, } \\
\text { Capability Expansion, } \\
\text { Focus on Most } \\
\text { Vulnerable }\end{array}$ & $\begin{array}{c}\text { Values States of Being } \\
\text { (freedom) } \\
\text { Capabilities } \\
\text { Individual Agency } \\
\text { Social Institutions }\end{array}$ \\
\hline
\end{tabular}

Source: [29].

Just as the sustainability principles embrace the trade-offs among the economic, social, and environmental considerations, so too do the SD strategies. The appropriateness of a SD strategy will depend on the reality of a given situation. None of the SD strategies are necessarily better or worse, but they do have their respective advantages and disadvantages in different contexts. For example, economic choice has the advantage of being easily operationalized within existing societal structures, and social choice has the advantage of considering the needs of disadvantaged individuals and communities [30]. The selection of SD strategies influences whether an energy transition will occur quickly or slowly [31].

Today, the continued relevance of the SD concept is reflected in the establishment of the 17 international SD goals [32] and 13 aspirational Canadian SD goals [33]. Drawing from SD goals to guide governance is "new and unique for a number of characteristics such as the inclusive goal-setting process, the non-binding nature of the goals, the reliance on weak institutional arrangements, and the extensive leeway that states enjoy" [34] (p. 26). The main limitation is that $\mathrm{SD}$ goals need to be continuously updated because of the evolving expectations and values of society. Any SD goals that we set for ourselves today are not going to be identical to the SD goals that we will set for ourselves in 2050. That is to say, the United Nations Millennium Development Goals were appropriate in 2000, but needed to be updated in 2015. Therefore, SD goals complement both sustainability principles and SD approaches, but do not replace them (i.e., the development of SD goals should be informed by sustainability principles, and the overall direction of the SD approaches should be towards the SD goals).

\subsection{Key Theme \#3: Energy Transitions Require Collaboration and Dialogue}

SD provides us with a useful concept to identify and assess the social, environmental, and economic considerations associated with energy transitions. However, if energy 
transitions are going to be successful, then we need to recognize that "developments in the societal and political spheres largely determine the ideas that gain currency and acquire practical force" [35] (p. 338). Therefore, it is imperative to understand the expectations, values, and priorities of the people that will be affected by energy transitions. The best way to understand these societal expectations, values, and priorities is to engage directly with citizens.

Collaboration and dialogue are useful when confronted with "values driven dilemmas, complex problems that require trade-offs, and long-term issues that go beyond the short-term incentives of electoral cycles" [36], such as sustainability challenges in the energy system. Collaboration and dialogue include widespread, broad participation and focused deliberation with subsets of the population. Some suggest that finding the correct balance between broad and in-depth participation can be a powerful combination [37]. Effective collaboration and dialogue result in better decisions, increase the legitimacy of public institutions when confronted with difficult decisions [38], promote and accelerate sustainability transformations [39], and strengthen governance approaches [40].

Energy transitions are complex, so collaborative approaches are needed to increase the shared understanding between divergent perspectives [8]. For example, the idea of a just transition aims to move towards a low-carbon future, equitably assist people who are negatively affected by the move to a low-emissions future (e.g., workers who lose their jobs when a coal mine is closed), and address the 1.6 billion people around the world without electricity [41]. The ability to transition to a just and equitable energy system will depend on, among other things, education and behavioural changes [42].

When considering the importance of collaboration and dialogue for the energy transition, the social choice strategy within the human development approach stands out as particularly relevant. This is because social choice places emphasis on identifying needs and priorities through deliberative processes where there is freedom of discussion and freedom of political participation [11].

\subsection{Key Theme \#4: Social Innovation Can Help Drive Energy Transitions}

Collaboration and dialogue can be a powerful source of innovative solutions. Innovation is the process of spreading ideas throughout society, whereas invention can be considered to be the process of creating and implementing new ideas [43]. Innovation includes both the diffusion of ideas and the ability to promote changes in energy systems [44]. As such, technological inventions without innovation will be insufficient to solve the challenges of energy transitions.

Social innovation is an important concept within innovation studies. There is general agreement that the concept of social innovation relates to systemic change that is good for society and which is based on participative social interactions [45]. One definition of social innovation that is useful for our work in the energy system is "innovations that are social in both their ends and their means", which acknowledges the importance of ends (i.e., new products, services, and models that address social demands and societal challenges) and means (i.e., the process of social inclusion) [46] (p. 24). It matters how the ends are achieved (as opposed to the ends justifying the means). The means of social innovation in an energy transition include emissions reductions and collaboration, whereas the ends of social innovation in an energy transition include social goals, such as "alleviating (energy) poverty, (energy) justice, social equality, and increasing the wellbeing of local communities" [47] (p. 10).

In the past 10 years, there have been efforts to link the concepts of social innovation and SD. For example, social innovation researchers recognize that social challenges (e.g., poverty and equality) and planetary challenges (e.g., climate change) are closely linked [48]. In order to solve these sustainability challenges, social innovation researchers will have to "shift resource and authority flows, social routines and cultural values of the social system that created the problem in the first place" [49] (p. 4). Some social innovation researchers recommend using "change labs" to test ideas and build knowledge so that solutions are 
available when the timing is right [43]. The Energy Futures Lab is an example of such a "change lab" seeking to incorporate social cohesion, trust, and SD into the energy transition in Canada.

\section{Case Description}

\subsection{The Energy Transition in Canada}

Canada is a significant global energy producer: it is the second-largest hydroelectricity producer, the fifth-largest natural gas producer, the sixth-largest crude oil producer, and the seventh largest with respect to installed wind power capacity [50]. Canada is a significant global energy producer that emitted a total of 730 megatonnes of carbon dioxide equivalent in 2019 [51], which contributed to Canada being one of the highest global GHG emitters on a per capita basis [52].

The total end-use energy demand by Canadians was 11,489 PJ in 2017, which includes $52 \%$ from the industrial sector, $23 \%$ from the transportation sector, $13 \%$ from the residential sector, and $12 \%$ from the commercial sector [52]. Canada has a higher per capita energy consumption (i.e., approximately 300 GJ per capita per year) compared to the global per capita energy consumption (i.e., approximately 80 GJ per capita per year), which can largely be explained by Canada's "geography, geology, settlement patterns, and resource-based, energy intensive industrial development" [53] (p. 22). For example, Canada has a cold northern climate that requires household heating, and a dispersed population that travels greater distances to transport goods. Canada has the second highest energy intensity for OECD countries at 7.70 MJ per CAD 2011 GDP [50]. To further complicate the challenges of the energy transition, there are estimates of a potential $50 \%$ increase in population in Canada over the next 50 years due primarily to immigration [54].

The energy system in Canada has evolved in a comparable manner to that of other modern countries, such as with a drastic increase in the total amount of energy consumed and shifts from biofuels, to coal, to oil and natural gas [55]. However, there are notable differences, including the tendency for Canada to consume more energy per capita than other countries (as discussed above), to consume a wide variety of energy sources, to export a lot of energy, and to be a slow adopter of alternative energy sources and conversions [53].

The energy transition in Canada is also influenced by the legal and constitutional arrangements between various levels of government (i.e., federal, provincial, territorial, municipal, and Indigenous governments) [56]. Section 92(A)(1) of the Canadian Constitution Act, 1867 indicates that each province may exclusively make laws in relation to non-renewable natural resources. Section 35(1) of the Canadian Constitution Act, 1982 states that the existing Aboriginal and treaty rights of the Aboriginal peoples of Canada are hereby recognized and affirmed. This means that provincial governments, such as the province of Alberta, and Indigenous governments have an important role to play in the energy transition [42].

There are many initiatives across Canada focused on the energy transition, including the Energy Futures Lab.

\subsection{Canada's Energy Futures Lab}

The Energy Futures Lab (EFL) was started in 2014 by Natural Step Canada in recognition of the challenges and opportunities created by changes in the global energy system. The EFL brings together thought leaders, innovators, and influencers (i.e., a design and delivery team, a group of approximately 60 Fellows from across the energy system, an advisory council, a steering committee, and funding partners) to discuss, experiment, and innovate energy solutions. The EFL design and delivery team is responsible for the day-to-day operations of the EFL, including the design of fellowship workshops, strategic communications, network alignment, project management, and regular convenings. The Fellows are expected to participate in interactive fellowship workshops, develop collaborative solutions, inspire action on innovation challenges, and share relevant ideas with their networks. The Fellows represent a diversity of views on the energy system, including 
the perspectives of Indigenous and non-Indigenous practitioners currently working for governments (i.e., federal, provincial and rural, and urban municipalities), NGOs, renewable energy companies, oil and gas companies, financial institutions, academia, and artistic endeavours (e.g., theatre, film, and print making).

The EFL is guided by the science-based and systems thinking framework of Natural Step (i.e., the Framework for Strategic SD). This framework contains four sustainability principles (see Table 2) that guide decision making within complex systems. For example, these sustainability principles are used to help manage difficult trade-offs, leverage the assets of and relationships among existing social institutions, and engage in constructive conversations [57]. Based on these sustainability principles, the EFL defines the following 2050 vision for the energy system the future requires of us [58], which:

- Is net zero for carbon emissions for the production and consumption of energy in Alberta and Canada.

- Enables a good quality of life for all people by meeting energy needs reliably and affordably.

- Is a leader in energy-based partnerships towards reconciliation with Indigenous peoples in Canada.

- Is inclusive, accessible, and equitable to current and future generations.

- Enhances the health of our natural environment and the health of all those living within it.

- Is a continued source of economic prosperity for the province and the country.

- Supports diversity, resiliency, and adaptability.

It is often a challenge to evaluate the success of initiatives, such as the EFL, in shaping the energy transition. However, research has been recently completed on whether the EFL is effectively supporting a sustainability transition. In particular, Steve Williams developed an evaluation framework that covers the process, the societal effects, and the sustainability transition impacts of sustainability transition experiments, and presented the following conclusions [59] (pp. 333-334):

- Regarding the process, the EFL has demonstrated "commitment to fairness, inclusivity, and transparency in its process design and implementation", but more work could be conducted in the area of reconciliation with Indigenous peoples;

- Regarding societal effects, the EFL has demonstrated successes, such as building individual capacity, promoting social and technical innovation, improving professional networks, and some instances of changing policies and organizational decision making;

- Regarding sustainability transition impacts, the EFL has demonstrated "new forms of governance and actor engagement", but more work could be conducted to influence the transition of the energy system.

We were interested in conducting further research on the EFL for two reasons. First, conducting our research in 2021 afforded the EFL additional years to mature as an initiative. Second, we relied on a different theoretical framework to guide our research, which had the potential to produce different findings.

\section{Materials and Methods}

To evaluate our theoretical framework, we interviewed a sample of experts working on the energy transition in Canada to determine to what degree their practice matches the key themes identified in the academic literature. We considered experts to be people with specific knowledge in a clearly defined subject matter (in this case energy transitions), actively influencing decision making in their field [60]. By following this definition of experts, we were interested in finding people with specific knowledge about energy systems who are actively working on the energy transition and influencing energy policy and decision making. As a result, our research focused on Canada's Energy Futures Lab (EFL), 
which is a social innovation lab leveraging today's energy system to create the energy system that the future requires of us (see Section 3.2).

In order to understand how well practitioners in the EFL align with the key themes identified in the academic literature, we conducted in-depth interviews with members of the EFL design and delivery team. In-depth interviews involve "asking questions and following up on the responses of the interviewee in an endeavour to extract as much information as possible from a person (the interviewee) who has expertise on the topic/s the interviewer is interested in" [61] (p. 3). Our interview questions explored both systemic ideas (e.g., understanding the strategies used by the EFL, the innovative processes of the EFL, the innovative outcomes of the EFL, and the obstacles faced by the EFL) and theory-generating ideas (e.g., understanding Canada's energy system and the energy transition) [60].

The interview guide was developed after the initial theoretical framework had helped to identify the following three themes: energy transitions require a systems perspective; energy transitions involve social, environmental, and economic considerations; and social innovation can help drive energy transitions. The fourth theme (i.e., energy transitions require collaboration and dialogue) emerged from the interviews, which was then iteratively incorporated as a key theme into the theoretical framework.

We interviewed five members of the EFL core design team who have been with the initiative since its inception. This is a type of purposeful sampling used to look for experts who are "most likely to give rich, informative interviews about the research questions under review" [61] (p. 63). We took interview notes and validated the interview summaries with the research participants. Our interview guide was informed by the key themes identified in the academic literature and relied on semi-structured, in-depth interview questions, such that we focused on our research questions, but also accommodated "the respondent's more spontaneous descriptions and narratives" [62] (p. 470).

We used content analysis to analyse the results of our in-depth interviews, understood here as the "intellectual process of categorizing qualitative textual data into clusters of similar entities, or conceptual categories, to identify consistent patterns and relationships between variables or themes" [62] (p. 120). Coding is an iterative process that involves reviewing data in order to identify key words or concepts that appear to be of potential theoretical significance and/or that appear to be particularly relevant to the research questions [63]. It is iterative because it can evolve and undergo refinements as the researcher works with the data [62]. Our approach to coding identified key words and concepts, both explicit and implicit, that reflect the key themes of our theoretical framework. Our coding process was iterative, similar to the development of the four themes, insofar as we started by coding for our initial three themes from our theoretical framework, but added additional coding to support the fourth theme (i.e., energy transitions require collaboration and dialogue) after the interviews were completed. When discussing the results of our interviews, we use the term "all interviewees" when there was explicit support from all five interviewees, and we use the term "the majority of interviewees" when there was explicit support from at least three of the interviewees (and no explicit disagreement from others).

\section{Results}

\subsection{Energy Transitions Require a Systems Perspective}

All interviewees expressed belief that one of the keys to success for the EFL was the decision to adopt systems thinking for Canada's energy transition. One interviewee stated:

To truly align Canada's energy system with the sustainability principles, we need to take a systems-based approach and employ strategies that work for all aspects of the system. We do ourselves a disservice if we only focus on those elements of the system that are currently top of mind for some people.

The EFL mapped out the energy system to build a shared understanding among the different actors in the energy system. The energy system was defined to include the production and consumption of energy in the transportation, residential and commercial, 
industrial, and agricultural sectors. The majority of interviewees stated that any changes to the energy system should consider the intended and unintended consequences to these sectors. A shared understanding among the different actors in the energy system makes it easier to understand how each other's interests may be positively and negatively affected by changes. One interviewee stated:

The systems level perspective of the EFL is innovative. We are not focused on promoting change in one specific sector (e.g., transportation, commercial, industrial or agricultural), in one specific organization, or in one specific niche-level initiative but rather broader system level change.

All interviewees indicated that another important systems thinking implication is the need to consider the social, environmental, and economic aspects of the energy transition. Environmental considerations are important, but this breadth has allowed the EFL to embrace many of the social (e.g., reconciliation with Indigenous peoples, energy poverty, just transitions, and energy literacy) and economic aspects (e.g., sustainable finance, energy efficiency for small rural businesses, and community power generation) of the energy transition. One of the interviewees indicated that failing to consider these aspects of the energy system will increase the possibility of replicating some of the flaws of the old system when creating the new system (e.g., systemic racism).

The inclusion of social, economic, and environmental considerations makes it difficult for the EFL to address all challenges in the energy system. Interviewees indicated that the projects of the EFL are not a comprehensive set of solutions, but rather exemplify important pathways. The EFL projects move us in the right direction, but there are missing elements in their work.

\subsection{Energy Transitions Involve Social, Environmental, and Economic Considerations}

All interviewees indicated that much of the focus of Canada's energy transition is currently on climate change, and this is, indeed, an essential component of the energy transition. Climate change represents a massive and growing societal concern because of its impacts on all three of social, environmental, and economic dimensions. The interviewees felt strongly that much more work needs to be conducted in this area; however, they did not believe that this sole focus can deliver, by itself, the energy system that the future requires of us. Affordability and reliability must also be considered in the energy transition, including economic factors, such as the median levelized costs of generating electricity. If these are not considered in the energy transition, then the energy system of the future will contribute to the creation of a more unequal society in Canada. All interviewees agreed that there are many competing societal challenges associated with energy transitions, and that these have been exacerbated by the COVID-19 pandemic. There were many reasons identified by the interviewees as to why SD is relevant for guiding their work on the energy transition, including that SD [10]:

- Covers the social, environmental, and economic aspects of the energy system;

- Is sufficiently broad to include the perspectives of government, industry, and civil society;

- Incorporates both renewable and non-renewable resources in the energy system;

- Incorporates both the production and consumption of energy;

- Applies systems thinking;

- Addresses intergenerational equity and justice (i.e., current and future generations).

All interviewees identified SD as an essential concept to inform their efforts to align the energy system with the scientific principles of sustainability. One interviewee stated:

The sustainability principles have been developed by the scientific community associated with the Natural Step. These principles can be used to provide rigour to conversations about the SD definition, SD strategies and SD goals. If we fail to align our activities with the sustainability principles, then we will undermine our ability to meet our current needs and the needs of future generations. 
Sustainability principles do not dictate that we should never disturb a natural landscape, nor that we should immediately stop using all materials that are extracted from the Earth. Rather, the principles suggest that sustainable societies need to focus on areas subject to systematic increases. Therefore, the extraction of fossil fuels can potentially align with the sustainability principles, provided that there is no systematic accumulation in greenhouse gas emissions or other substances from the Earth's crust, just as the extraction of minerals can potentially align with the sustainability principles, provided that there is no systematic degradation of nature from mining operations. This led the EFL's diverse participants to adopt a vision that commits to being net carbon neutral by 2050 and exploring pathways such as a hydrogen economy, carbon capture, utilization and storage, and bitumen beyond combustion (e.g., thinking about fossil fuels containing carbon as a material and hydrogen as an energy source). This vision of being net carbon neutral may not sound impressive in 2022 (e.g., there are numerous pledges being made by companies and governments to achieve carbon neutrality by 2050), but it was a significant step for the EFL in 2015 before the Paris Agreement was created and net-zero pledges became more widespread in 2019 and 2020. Several interviewees mentioned that creative ideas from the EFL from five years ago almost appear inevitable today.

All interviewees indicated that it is important to adopt an ends-based orientation (e.g., relying on the principles of sustainability) for the energy transition, as opposed to focusing solely on one important means (i.e., addressing climate change). The means and ends for any specific energy transition should be informed by societal expectations, values, and priorities. One interviewee stated:

When you define a different end state, then it is possible to address issues that appear to be "either-or" challenges. It becomes possible to design the trade-offs out of the system.

SD shapes all the work of the design team, even though it is not always explicitly highlighted during the internal work or in external communications. At the beginning of the EFL in 2014, there was a conscious effort to keep the concept of SD somewhat under the radar in order to appeal to as many actors as possible in the energy system. The interviewees had concerns that the numerous different public perceptions and interpretations of SD could limit our ability to set the new initiative in motion.

Each of the interviewees had slightly different definitions of SD and their own ideas about the priorities for Canada's energy system based on those definitions. However, all interviewees indicated that multiple strategies (i.e., economic choice, political choice, and social choice) should be explored in the energy transition. The main reason given is the belief that there are a wide range of pathways to a better future. By exploring multiple strategies, the interviewees felt that actors in the energy system would have greater creative freedom to design and implement strategies that make sense for any given opportunity. These strategies could result in incremental and transformative improvement in the energy system if they are appropriately modified to be region-specific. None of the interviewees felt that it would be wise to limit the energy transition to only one of the strategies (e.g., why would you put all your eggs in a single basket?). One interviewee stated:

All of the potential strategies in the energy transition are important and interrelated. You can't focus on only one. It is essential to explore as many options as possible in order to design flexible platforms that take us in the right direction.

In order to explore multiple strategies, the majority of interviewees considered the energy transition to be a process, as opposed to a goal that needs to be achieved. One interviewee stated:

The energy transition is a process that will unfold over many years so we shouldn't expect any single strategy, or project, or individual to be able to solve the problems of the energy system.

Goals and interim goals can be useful to mobilize resources in certain areas, but they often reflect the realities and values of society at a given point in time and, therefore, need 
to be continually refreshed. For example, in the year 2030, the United Nations will need to update the SD goals such that they are applicable for the new realities and sustainability challenges that the world is facing. One of the interviewees mentioned that the goals for Canada's energy system today are very different from the goals 100 years ago or 100 years into the future. This is why the EFL decided to create a vision for the energy system by backcasting from the sustainability principles (as opposed to backcasting from a future scenario). The design team felt that it would have been too difficult to induce 60 Fellows with different perspectives of the energy system to agree on a desirable future scenario for the energy system, but it was more feasible to gain broad agreement on success principles.

\subsection{Energy Transitions Require Collaboration and Dialogue}

All interviewees indicated that one of the keys to success for the EFL is a focus on collaboration and dialogue. They commented that this is important in the world today because social media makes it easy for people to connect only with other people who share similar perspectives. This is important today in Canada's energy system because the current conversations are polarized (e.g., economy vs. environment, us vs. them, fear vs. opportunity). One of the objectives of the EFL is to find common ground among the different actors in the energy system, which includes environmental organizations, Indigenous leaders, incumbent energy system players, technology innovators, different levels of government, etc. The EFL was not necessarily seeking agreement on the details of the future energy system, but rather common ground on the principles of a successful energy system that could form the basis of a common direction and a wide range of possible pathways that move us towards that future. One interviewee stated:

The EFL is a forum for collaboration. We are a broker of hope and possibility by hosting solution-oriented conversations. We act as a bridge between different actors in the energy system (e.g., government, industry, and citizens) as well as different ideas in the energy system (e.g., net zero, innovation, investment, reconciliation, just transitions, affordability).

The interviewees indicated that the EFL designed its processes to build trust amongst the Fellows, which in turn allows the Fellows to have meaningful dialogue within the EFL. The interviewees heard directly from Fellows that these conversations enable Fellows to better understand the perspectives of other actors in the energy system and expand the Fellows' thinking about the challenges in the energy system. The Fellows can then carry this deeper understanding and expanded thinking into conversations beyond the EFL in their respective spheres of influence. In this manner, the benefits of collaboration and dialogue are spread to other actors in the energy system. One interviewee stated:

The Fellowship model is unique. The long-term commitment of the Fellows allows the lab to build social capital and as the level of social capital builds, the nature of the conversation changes. We create a safe place for important but difficult conversations between people that hold different perspectives - this is true dialogue.

Collaboration and dialogue often involve unusual partnerships. One example from the EFL is the unlikely partnership and pursuit of collaborative opportunities between the CEO of a midstream natural gas infrastructure company and the CEO of a geothermal company who hold two different visions for Canada's energy system [64]. Another example is the EFL roadshow, where the design team and Fellows travel physically or virtually to rural municipalities to understand the local perspective, share ideas on how to move forward, and expand everyone's thinking about the sustainability challenges in the energy system. Another example cited is the creation of a lithium industry (e.g., a fundamental component for batteries in electric vehicles and large-scale energy storage) that applies oil and gas expertise to extract the resource from oilfield wastewater.

The EFL attempts to design an inclusive and generative space that promotes the cocreation of knowledge about energy solutions. This solutions-oriented approach encourages people with diverse perspectives in the energy system to take the time to listen to one 
another. The interviewees indicated that collaboration and dialogue have the potential to enhance all strategies (i.e., economic choice, political choice, and social choice).

\subsection{Social Innovation Can Help Drive Energy Transitions}

All interviewees mentioned the importance of social innovation to the success of the EFL. The purpose of a social innovation lab is to seek a broad range of constructive solutions to move things forward, together. As a result, the interviewees designed processes to offer a co-creative and generative space, as opposed to a space for debating and negotiating existing positions. This overall approach has been noted as refreshingly different, with interviewees reporting that the feedback from many Fellows to the design team was that the spirit and energy of the EFL processes felt different from other initiatives. These processes were less about brokering interests and more about co-creating solutions. By investing in social innovation and building trust amongst the Fellows, the EFL tackled difficult conversations that would be impossible in other situations (e.g., emotional, personal, or sensitive topics). Interviewees indicated that social innovation has influenced both the processes and outcomes of the EFL.

Part of moving things forward, together, is to include the perspectives of different people that are affected by the energy transition, and to recognize that different people are affected differently by the energy transition. This is why the EFL's vision mentions energy-based partnerships toward reconciliation with Indigenous peoples in Canada, and why efforts are made to overcome barriers for marginalized communities in the energy transition. One interviewee stated:

The transition in Canada's energy system is moving forward on many fronts but is increasingly obvious that not everyone is being brought along. In order to move forward, together, people need to be at the centre of the energy transition. If we fail to address the social obstacles (e.g., structural obstacles to people's health, influence, competence, impartiality and meaning), then the energy transition will not be successful.

One example that demonstrates the potential power of social innovation occurred during a workshop between the Fellows and a partner organization that provided input on a technology roadmap. Several interviewees indicted that the partner organization was satisfied with the Fellow input on the technology roadmap but, more significantly, the experience with the EFL had a broader influence on the philosophy of the organization in tackling future challenges. There appeared to be a cultural shift in the leadership of the partner organization. One interviewee stated:

Social innovation has the potential to accelerate Canada's energy transition. This means thinking beyond technical innovation, to consider elements such as, cultural shifts, narratives, policies, financing, participation, and trust.

The concept of social innovation has been embraced by the EFL since the beginning. The majority of interviewees indicated that processes to encourage technological innovation are reasonably well established in the Canadian energy system; however, processes to encourage social innovation are much less developed and have the potential to magnify the benefits of the technological innovation and directly produce benefits for the energy transition.

\section{Discussion}

\subsection{Innovation in Canada's Energy Transition}

The availability of energy sources in Canada is different from other parts of the world, which means that the options available for uses and conversions of energy will also be different. In addition, Canada consumes more energy per capita than other countries, consumes a wide variety of energy sources, exports a lot of energy, and tends to be a slow adopter of alternative energy sources and conversions [53]. This creates a unique set of societal expectations, values, and priorities. Our interviewees described the importance of keeping in mind this context when discussing the energy transition in Canada. 
In Canada, total energy use depends on the energy use in the industrial, residential, transport, and agricultural sectors. There are a variety of uses for energy that might be difficult to transform and require innovative solutions. For example, in the industrial sector, steel production currently relies on burning metallurgical coal, and cement production releases $\mathrm{CO}_{2}$ when limestone breaks down into calcium oxide; in the transportation sector, there are no immediate substitutes available for jet fuel; and in the agricultural sector, natural gas is a key ingredient for producing fertilizers. Initiatives such as the EFL, which adopt a systems perspective, complement other initiatives within Canada's energy system that take a narrower perspective, for example, initiatives focused on the environmental aspects related to the production of one type of energy. Neither perspective is necessarily correct or incorrect, but one should be mindful that each approach has the potential to reveal and conceal different aspects of the energy transition. One should also be mindful that technological inventions without innovation (i.e., spreading ideas throughout society) will be insufficient to solve the challenges of the energy transition.

Given the sustainability principles, there are several energy conversions that are, at first glance, more likely to be consistent with a sustainable energy system, for example, wind, geothermal, run-of-river hydro, tidal, and waste from energy. Based on today's technology, there are also many energy conversions that are, at first glance, less likely to be included in a sustainable energy system, for example, the combustion of fossil fuels (as nature is subject to systematically increasing concentrations of GHGs in the atmosphere), hydro-electric dams (as they degrade nature by obstructing rivers), and PV panels and batteries (as the mining of rare earth minerals and metals degrades nature). However, the details matter, meaning that it is important to understand how these energy sources and their conversions occur in relation to the sustainability principles, SD approaches, and SD goals. Further, the considerations for a specific region will depend on societal expectations, values, and priorities.

One element of the energy transition that has broad consensus, identified in our theoretical framework and interviews, is to waste less energy. If we improve energy efficiency across all sectors, then we will need to produce less energy and fewer environmental impacts. For example, studies indicate that increasing energy efficiency education will help improve energy efficiency levels in the residential sector in Canada [65]. Given the broad consensus, this element could be useful to establish common ground during collaboration and dialogue. Social innovation is closely linked with collaboration and dialogue. The interviewees consider the EFL to be a social innovation lab, and could not imagine the lab without a strong foundation of meaningful collaboration and dialogue among a diverse group of people. Our research suggests that social innovation can be strengthened by appropriately bringing together divergent perspectives and hosting difficult conversations.

It is important to note that social innovation, technological innovation, and increasing knowledge (e.g., our understanding of the natural world) could significantly improve when the uses and conversions of energy in the future are consistent with the sustainability principles. An example of this concept is blue hydrogen, produced from natural gas but carbon neutral because of carbon capture technologies, zero degradation of nature because it happens on previously disturbed sites, and positive social impacts because it directly advances reconciliation with Indigenous peoples. Therefore, one could have the counter-intuitive situation whereby blue hydrogen from natural gas meets the test for a sustainable energy source, whereas electricity generated from a hydro-electric dam does not, because the dam is degrading nature by physical means. However, there is no guarantee that increasing knowledge, technological innovation, and social innovation will solve the sustainability challenges of the energy transition in a timely manner. Hope is not a plan. We need to dedicate resources and embrace innovation that takes us on "an open-ended journey of creation and exploration" [66] to solve the problems of the energy transition. 


\subsection{Governance in Canada's Energy Transition}

Governance can be thought of as "the sum of the many ways individuals and institutions, public and private, manage their common affairs" [67] (p. 2). Our research indicates that there are divergent perspectives about how to manage common affairs during the energy transition in Canada. For example, the interviewees described different societal expectations for the uses and conversions of energy in Canada, which creates tensions, trade-offs, and synergies in the energy transition. As we have already discussed in our theoretical framework, SD is a dynamic process that meets the needs and prompts the capabilities of the current generation without compromising future generations [10-12]. SD provides us with a useful evaluative concept to manage these common affairs, a concept that moves us away from ideology and politics into evidence-based scientific decision making, and a concept that moves us beyond polarized conversations and drives aspects of the energy transition in Canada. Energy sources, such as electro-magnetic, chemical, nuclear, kinetic, thermal, and electrical energy, are neither good nor bad. What matters is how these energy sources and their conversions occur in relation to the sustainability principles, SD approaches, and SD goals.

The energy transition in Canada is a dynamic process and there are solutions of different shapes and sizes. There is no need to agree on a set of solutions or a single pathway that defines success. Solutions that resonate with citizens will gather energy and momentum, whereas solutions that fail to capture society's collective imagination will not be as successful. The generative space of the EFL is about creating something new, as opposed to tearing something down. According to Buckminster Fuller: "you never change things by fighting the existing reality. To change something, build a new model that makes the existing model obsolete" [68] (p. 358). The lessons outlined in the $\mathrm{EFL}$, as described in the earlier sections, might be more broadly applicable to address the challenging situation of Canada's governance systems (e.g., differing interests are at play) for the energy transition.

Viewing the energy system as an evolving process opens the idea of multiple strategies and pathways. Economic choice (e.g., relying on market mechanisms to promote ESG), political choice (e.g., relying on government intervention to establish a price on carbon, a critical habitat for endangered species, or subsidies for specific elements in the energy system), social choice (e.g., relying on the values of citizens to identify and develop the capabilities of our most vulnerable), and associated tools should all be considered to accelerate the energy transition. Civil society, government, and industry can create and advance different strategies and pathways; however, we need a feedback loop to know if these efforts are moving society in the right direction. If we recognize that problems are inevitable, then it is important for an evolving process to include a mechanism to identify problems so that we can correct our mistakes and solve our next problems [66]. A particular strategy might not be useful in a given situation today, and might be responsible for making the situation worse, but might be useful in the future. This can be a challenge for academics and practitioners who have a preconceived notion about how the transition should unfold.

Figure 1 provides an illustration of our Integrated Model of SD that includes the major elements of SD, including SD approaches, sustainability principles, and SD goals. This Integrated Model of SD can act as a useful governance framework to manage the common affairs of the energy transition and evaluate whether progress is being made.

There are several similarities between this integrated model of SD and social innovation. For example, they are both problem-focused and address both the ends and means of the process. The main difference between the two approaches is how they address the normative aspects of progress. SD has well-established sustainability principles and SD approaches (i.e., the capital theory approach and human development approach) that can be used to evaluate whether a policy, program, or initiative is moving towards sustainability. The normative aspects of progress are important in energy transitions because there are different societal expectations, values, and priorities. Perhaps there is an opportunity for 
social innovation researchers to embrace the sustainability principles to evaluate the ends and means of social innovation more transparently.

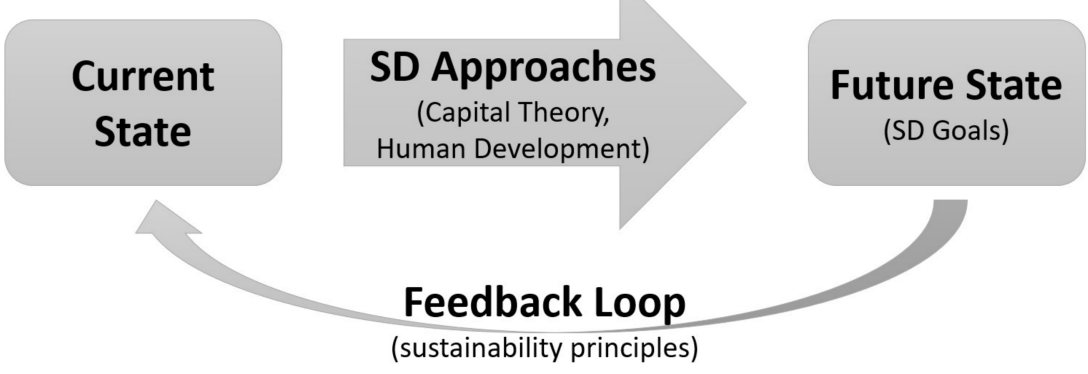

Figure 1. Integrated Model of SD. Source: created by authors.

\section{Conclusions}

Our research suggests that SD is one of the few concepts that embraces the key themes that should be addressed in energy transitions: a systems perspective; social, environmental, and economic considerations; collaboration and dialogue; and social innovation. In addition, SD provides a framework to manage the tensions and trade-offs associated with an energy transition. As a result, SD is not only useful, but necessary to navigate the complexities associated with Canada's energy transition. Interestingly and paradoxically, our research also suggests the explicit use of the concept may not be helpful (and may potentially be counter-productive) because of the different, sometimes negative, interpretations of SD by the public.

Our research has theoretical and practical contributions. From a theoretical perspective, both the ends and the means are important to consider in an energy transition. There are many important means in the energy transition, for example, reducing greenhouse gas emissions, reconciling with Indigenous peoples, protecting biodiversity, decreasing inequality, alleviating energy poverty, improving energy efficiency, removing anthropogenic nitrogen, and collaborating with citizens, and we must continue to make progress on each of these during the energy transition. However, these means should not be conflated with the desired end of having an energy system that aligns with the principles of sustainability. If energy transitions are steered to focus on only one particular means (as opposed to the end), then there is an increased risk of making sup-optimal decisions because of missing material considerations. Given that different countries have different uses and conversions of energy, and different priorities for their own energy transitions, there are a wide range of possibilities to manage tensions, trade-offs, and synergies, and a wide range of possibilities for aligning their energy systems with the principles of sustainability. Not only is there a plurality of potential pathways today, but there also exists many different future visions of a desired end for the energy system of a given country.

From a practical perspective, SD can inform a collaborative approach to addressing complex sustainability challenges. Often, SD is used in a polarizing manner to challenge the status quo, to point out deficiencies, and to highlight where we are falling short of achieving a perfectly sustainable society, which can be a powerful force in promoting action and making change happen. However, an equally important role for SD is to bring people together. Collaboration and dialogue promote social innovation and increase societal knowledge, which are critical to ensure that the energy transition provides universal access to affordable, reliable, sustainable, and modern energy [32].

Author Contributions: Conceptualization, M.B.; methodology, M.B., C.B., R.R.D., and L.K.; formal analysis, M.B.; data curation, M.B.; writing—original draft preparation, M.B.; writing-review and editing, M.B., C.B., R.R.D., L.K., and C.P.; supervision, L.K. All authors have read and agreed to the published version of the manuscript.

Funding: This research received no external funding. 
Institutional Review Board Statement: The study was approved by the Research Ethics Board of Royal Roads University on 8 January 2021.

Informed Consent Statement: Informed consent was obtained from all subjects involved in the study. Data Availability Statement: Not applicable.

Conflicts of Interest: M.B. is a doctoral candidate at Royal Roads University, and he works for the Canada Energy Regulator and the Sustainable Energy Development Program at the University of Calgary. M.B. is currently a Fellow in the Energy Futures Lab. C.P. works for the Cooperators Group Limited. C.P. is currently a Steering Committee Member of the Energy Futures Lab and was part of the Energy Futures Lab design and delivery team from 2014 until 2020. The views expressed in the journal article are those of the authors and not of the organizations they work for.

\section{References}

1. International Energy Agency. Net Zero by 2050; International Energy Agency: Paris, France, 2021. Available online: https: //www.iea.org/reports/net-zero-by-2050 (accessed on 12 November 2021).

2. Generation Energy Council. Canada's Energy Transition: Getting to Our Energy Future, Together; Generation Energy Council: Ottawa, ON, Canada, 2018. Available online: https://www.nrcan.gc.ca/sites/www.nrcan.gc.ca/files/energy/CoucilReport_july4_EN_ Web.pdf (accessed on 12 November 2021).

3. Kates, R. What Kind of a Science Is Sustainability Science? Proc. Natl. Acad. Sci. USA 2011, 108, 19449-19450. [CrossRef]

4. Kates, R.W.; Clark, W.C.; Corell, R.; Hall, J.M.; Jaeger, C.C.; Lowe, I.; McCarthy, J.J.; Schellnhuber, H.J.; Bolin, B.; Dickson, N.M.; et al. Sustainability science. Science 2001, 292, 641-642. [CrossRef] [PubMed]

5. IEA; IRENA; UNSD; WB; WHO. Tracking SDG 7: The Energy Progress Report; World Bank: Washington, DC, USA, 2019. Available online: https:/ trackingsdg7.esmap.org/data/files/download-documents/2019-Tracking\%20SDG7-Full\%20Report.pdf (accessed on 12 November 2021).

6. World Bank. Poverty and Shared Prosperity 2020: Reversals of Fortune; World Bank: Washington, DC, USA, 2020. Available online: https:/ / www.worldbank.org/en/publication/poverty-and-shared-prosperity (accessed on 12 November 2021). [CrossRef]

7. Raworth, K. Doughnut Economics: Seven Ways to Think Like a 21st Century Economist; Chelsea Green Publishing: Hartford, VT, USA, 2017.

8. Jasanoff, S. Just transitions: A humble approach to global energy futures. Energy Res. Soc. Sci. 2018, 44, 11-14. [CrossRef]

9. Hegre, H.; Petrova, K.; von Uexkull, N. Synergies and Trade-Offs in Reaching the Sustainable Development Goals. Sustainability 2020, 12, 8729. [CrossRef]

10. World Commission on Environment and Development. Our Common Future; Oxford University Press: Oxford, UK, 1987.

11. Sen, A. The Ends and Means of Sustainability. J. Hum. Dev. Capab. A Multi Discip. J. People Cent. Dev. 2013, 14, 6-20. [CrossRef]

12. Clark, W. Sustainable Development and Sustainability Science. Draft Manuscript for Sustainability Science: An Introduction by Partha Dasgupta. 2010. Available online: https://groups.nceas.ucsb.edu/sustainability-science/2010\%20weekly-sessions/session-2-09.2 0.2010-sustainability-science-and-sustainable-development/required-readings-from-the-book/1_1_Sustsci\%20-\%20Sust \%20 Dev_vS2.pdf/at_download/file (accessed on 12 November 2021).

13. Frantzeskaki, N.; de Haan, H. Transitions: Two Steps from Theory to Policy. Futures J. Policy Plan. Futures Stud. 2009, 41, 593-606. [CrossRef]

14. Rotmans, J. Societal Innovation: Between Dream and Reality Lies Complexity; Erasmus Research Institute of Management: Rotterdam, The Netherlands, 2005; Available online: https: / / ssrn.com/abstract=878564 (accessed on 12 November 2021).

15. Bergek, A.; Jacobsson, S.; Carlsson, B.; Lindmark, S.; Rickne, A. Analyzing the functional dynamics of technological innovation systems: A scheme of analysis. Res. Policy 2008, 37, 407-429. [CrossRef]

16. Geels, F.W. The multi-level perspective on sustainability transitions: Responses to seven criticisms. Environ. Innov. Soc. Transit. 2011, 1, 24-40. [CrossRef]

17. International Labour Organization. Guidelines for a Just Transition towards Environmentally Sustainable Economies and Societies for All; International Labour Organization: Geneva, Switzerland, 2015. Available online: https://www.ilo.org/wcmsp5/groups/public/ ---ed_emp/---emp_ent/documents/publication/wcms_432859.pdf (accessed on 12 November 2021).

18. Markard, J.; Raven, R.; Truffer, B. Sustainability transitions: An emerging field of research and its prospects. Res. Policy 2012, 41, 955-967. [CrossRef]

19. Smil, V. Energy Transitions: Global and National Perspectives, 2nd ed.; Praeger: Santa Barbara, CA, USA, 2017.

20. Meadows, D.; Wright, D. Thinking in Systems: A Primer; Chelsea Green Publishing: White River Junction, VT, USA, 2008.

21. Smil, V. Energy and Civilization: A History; MIT Press: London, UK, 2018.

22. International Energy Agency; Organisation for Economic Co-operation and Development \& Nuclear Energy Agency. Projected Costs of Generating Electricity 2020; International Energy Agency: Paris, France, 2020. Available online: https://www.iea.org/ reports / projected-costs-of-generating-electricity-2020 (accessed on 12 November 2021). 
23. National Renewable Energy Laboratory. Life Cycle Greenhouse Gas Emissions from Electricity Generation; National Renewable Energy Laboratory: Golden, CO, USA, 2021. Available online: https://www.nrel.gov/analysis/life-cycle-assessment.html (accessed on 16 January 2021).

24. Robert, K.H. Natural Step: A Framework for Achieving Sustainability in Our Organizations; Pegasus Communications Inc.: Arcadia, CA, USA, 1997.

25. Natural Step. The Four System Conditions of a Sustainable Society; Natural Step: Nacka, Sweden. Available online: www. thenaturalstep.org/approach (accessed on 12 November 2021).

26. Missimer, M.; Robèrt, K.-H.; Broman, G. A strategic approach to social sustainability—Part 2: A principle-based definition. J. Clean. Prod. 2017, 140, 42-52. [CrossRef]

27. Natural Step Canada. Sustainability: Understanding the Problem; Natural Step Canada: Ottawa, ON, Canada. Available online: www.naturalstep.ca/sustainability (accessed on 12 November 2021).

28. Boda, C.; Scown, M.; Faran, T.; Nastar, M.; Dorkenoo, K.; Chaffin, B.; Boyd, E. Framing Loss and Damage from Climate Change as the Failure of Sustainable Development. Clim. Dev. 2021, 13, 677-684. [CrossRef]

29. Boda, C.; Faran, T. Paradigm Found? Immanent Critique to Tackle Interdisciplinarity and Normativity in Science for Sustainable Development. Sustainability 2018, 10, 3805. [CrossRef]

30. Boda, C.; Scown, M.; Faran, T. Forgotten coast, forgotten people: Sustainable development and disproportionate impacts from Hurricane Michael in Gulf County, Florida. Nat. Hazards 2021, 109, 1-23. [CrossRef]

31. Sovacool, B.K. How long will it take? Conceptualizing the temporal dynamics of energy transitions. Energy Res. Soc. Sci. 2016, 13, 202-215. [CrossRef]

32. United Nations. Transforming Our World: The 2030 Agenda for Sustainable Development; United Nations: New York, NY, USA, 2015 Available online: https://sustainabledevelopment.un.org/content/documents/21252030\%20Agenda\%20for $\% 20$ Sustainable\% 20Development $\% 20$ (accessed on 27 April 2021).

33. Environment and Climate Change Canada. A Federal Sustainable Development Strategy for Canada: 2019 to 2022; Environment and Climate Change Canada: Ottawa, ON, Canada, 2019. Available online: http://www.fsds-sfdd.ca/downloads/FSDS_2019-2022. pdf (accessed on 12 November 2021).

34. Biermann, F.; Kanie, N.; Kim, R. Global governance by goal-setting: The novel approach of the UN Sustainable Development Goals. Curr. Opin. Environ. Sustain. 2017, 26-31. [CrossRef]

35. Meadowcroft, J. What about the politics? Sustainable development, transition management, and long term energy transitions. Policy Sci. 2009, 42, 323-340. [CrossRef]

36. Organisation for Economic Cooperation and Development. Innovative Citizen Participation and New Democratic Institutions: Catching the Deliberative Wave; OECD Publishing: Paris, France, 2020. [CrossRef]

37. Carson, L.; Elstub, S. Comparing participatory and deliberative democracy. In newDemocracy Research and Development Note; newDemocracy Foundation: Royal Exchange, NSW, Australia, 2019. Available online: https://www.newdemocracy.com.au/wpcontent/uploads/2019/04/RD-Note-Comparing-Participatory-and-Deliberative-Democracy.pdf (accessed on 12 November 2021).

38. Chwalisz, C. The People's Verdict: Adding Informed Citizen Voices to Public Decision-Making; Roman \& Littlefield: New York, NY, USA, 2017

39. Wironen, M.; Bartlett, R.; Erickson, J. Deliberation and the Promise of a Deeply Democratic Sustainability Transition. Sustainability 2019, 11, 1023. [CrossRef]

40. Bulmer, E.; Prado-Higuera, C. Revitalizing the Global Alliances for Sustainable Development: Analyzing the Viability of Sustainable Development Goal 17-A Multi-Actor Governance Approach. Sustainability 2021, 13, 4247. [CrossRef]

41. Newell, P.; Mulvaney, D. The political economy of the 'just transition'. Geogr. J. 2013, 179, 132-140. [CrossRef]

42. MacArthur, J.L.; Hoicka, C.E.; Castleden, H.; Das, R.; Lieu, J. Canada's Green New Deal: Forging the socio-political foundations of climate resilient infrastructure? Energy Res. Soc. Sci. 2020, 65, 101442. [CrossRef]

43. Westley, F.; Olsson, P.; Folke, C.; Homer-Dixon, T.; Vredenburg, H.; Loorbach, D.; Thompson, J.; Nilsson, M.; Lambin, E.; Sendzimir, J.; et al. Tipping Toward Sustainability: Emerging Pathways of Transformation. AMBIO 2011, 40, 762. [CrossRef]

44. Hoicka, C.; Das, R.; Zhao, Y.; McMaster, M.; Lieu, J.; Wyse, S. Methodology to identify demand-side low-carbon innovations and their potential impact on socio-technical energy systems. MethodsX 2021, 8, 101295. [CrossRef] [PubMed]

45. Dias, J.; Partidário, M. Mind the Gap: The Potential Transformative Capacity of Social Innovation. Sustainability $2019,11,4465$. [CrossRef]

46. Bureau of European Policy Advisers. Empowering People, Driving Change: Social Innovation in the European Union; Publications Office of the European Union: Luxembourg, 2010. Available online: https:/ / ec.europa.eu/migrant-integration/?action=media download\&uuid=2A18225B-A4EF-443D-9D074439D071447D (accessed on 12 November 2021).

47. Hoppe, T.; de Vries, G. Social Innovation and the Energy Transition. Sustainability 2018, 11, 141. [CrossRef]

48. Olsson, P.; Moore, M.L.; Westley, F.; McCarthy, D. The concept of the Anthropocene as a game-changer: A new context for social innovation and transformations to sustainability. Ecol. Soc. 2017, 22, 31. [CrossRef]

49. Westley, F.; McGowan, K.; Tjörnbo, O. The Evolution of Social Innovation: Building Resilience through Transitions; Edward Elgar Publishing Limited: Cheltenham, UK, 2017. 
50. National Energy Board. Canada's Energy Transition: Historical and Future Changes to Energy Systems-Update; National Energy Board: Calgary, AB, Canada, 2019. Available online: https://www.cer-rec.gc.ca/en/data-analysis/energy-markets/canadasenergy-transition/ (accessed on 12 November 2021).

51. Environment and Climate Change Canada. National Inventory Report 1990-2019: Greenhouse Gas Sources and Sinks in Canada, Canada's Submission to the United Nations Framework Convention on Climate Change; Environment and Climate Change Canada: Ottawa, ON, Canada, 2021. Available online: https://publications.gc.ca/collections/collection_2021/eccc/En81-4-1-2019-eng. pdf (accessed on 12 November 2021).

52. Canada Energy Regulator. Canada's Energy Future 2019: Energy Supply and Demand Projections to 2040; Canada Energy Regulator: Calgary, AB, Canada, 2019. Available online: https:/ /www.cer-rec.gc.ca/en/data-analysis/canada-energy-future/2019/index. html (accessed on 12 November 2021).

53. Sandwell, R.W. Powering up Canada: A History of Power, Fuel and Energy from 1600; McGill-Queen's University Press: Montreal, QC, Canada, 2016.

54. Kerr, D. Population Growth, Canada's Energy Transition and Climate Change: A High Risk Future? Can. Issues 2018, 45-51. [CrossRef]

55. Unger, R.; Thistle, J. Energy Consumption in Canada in the 19th and 20th Centuries: A Statistical Outline; Consiglio Nazionale delle Richerche: Naples, Italy, 2013.

56. Sustainable Canada Dialogues. Re-Energizing Canada: Pathways to a Low-Carbon Future; Sustainable Canada Dialogues: Ottawa, ON, Canada, 2019. Available online: http:// sustainablecanadadialogues.ca/pdf_2017/ReEnergizing_Final.pdf (accessed on 12 November 2021).

57. Park, C. Blog: Chad Park Reflects on His Time with the EFL; Energy Futures Lab: Ottawa, ON, Canada, 2020. Available online: https:/ / energyfutureslab.com/chad-park-reflects-on-his-time-with-the-efl / (accessed on 25 June 2021).

58. Energy Futures Lab. Vision and Mission of the Energy Futures Lab; Energy Futures Lab: Ottawa, ON, Canada, 2021. Available online: https:/ / energyfutureslab.com (accessed on 12 November 2021).

59. Williams, S. The Splash and the Ripples: Assessing Sustainability Transition Experiments. Ph.D. Thesis, University of British Columbia, Vancouver, BC, Canada, 2019. Available online: https://open.library.ubc.ca/collections/ubctheses/24/items/1.0383 246 (accessed on 12 November 2021).

60. Bogner, A.; Littig, B.; Menz, W. Generating qualitative data with experts and elites. In The Sage Handbook of Qualitative Data Collection; SAGE Publications Ltd.: London, UK, 2018.

61. Morris, A. A Practical Introduction to in-Depth Interviewing; SAGE Publications Ltd.: London, UK, 2015.

62. Given, L.M. The SAGE Encyclopedia of Qualitative Research Methods; SAGE Publications, Inc.: Thousand Oaks, CA, USA, 2008. [CrossRef]

63. Bryman, A. Social Research Methods, 4th ed.; Oxford University Press: Oxford, UK, 2012.

64. Park, C. Unlikely Allies in the Oil Patch; Corporate Knights: Toronto, ON, Canada, 2019. Available online: https://www. corporateknights.com/leadership/finding-common-ground-in-oil-patch/ (accessed on 12 November 2021).

65. Das, R.; Richman, R.; Brown, C. Demographic determinants of Canada's households' adoption of energy efficiency measures: Observations from the Households and Environment Survey, 2013. Energy Effic. 2017, 11, 465-482. [CrossRef]

66. Deutsch, D. The Beginning of Infinity: Explanations that Transform the World; Penguin Books: London, UK, 2011.

67. Commission on Global Governance. Our Global Neighbourhood: The Report of the Commission on Global Governance; Oxford University Press: Oxford, UK, 1995.

68. Sieden, S. Fuller View—Buckminster Fuller's Vision of Hope and Abundance for All; Divine Arts Media: Kimball, MI, USA, 2011. 